\title{
Multicentre prospective phase II trial of gefitinib for advanced non-small cell lung cancer with epidermal growth factor receptor mutations: results of the West Japan Thoracic Oncology Group trial (WJTOG0403)
}

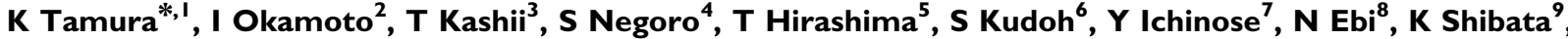 T Nishimura $^{10}$, N Katakami ' , T Sawa' ${ }^{12}$, S Shimizu ${ }^{13}$, J Fukuoka' ${ }^{14}$, T Satoh ${ }^{2}$ and M Fukuoka ${ }^{15}$}

'Outpatients Treatment Center, National Cancer Center Hospital, 5-I-I, Tsukiji, Chuo-ku, Tokyo 104-0045, Japan; ${ }^{2}$ Department of Medical Oncology, Kinki University School of Medicine, 377-2, Ohno-higashi, Sayama, Osaka 589-85 II, Japan; ' Department of Clinical Oncology, Osaka City General Hospital, 2-13-22, Miyakojima-hondori, Miyakojima, Osaka 534-002 I, Japan; ${ }^{4}$ Department of Thoracic Oncology, Hyogo Cancer Center, $13-70$, Akashi, Kitaouji, Hyogo 673-8558, Japan; ${ }^{5}$ Department of Thoracic Malignancy, Osaka Prefectural Medical Center for Respiratory and Allergic Diseases, 3-7-I, Habikino, Habikino, Osaka 583-8588, Japan; 'Department of Respiratory Medicine, Osaka City University Medical School, 1-5-7, Asahi, Abeno, Osaka 545-8586, Japan; 'Department of Thoracic Oncology, National Kyusyu Cancer Center, 3-I - I, Nodame, Minami, Fukuoka 81 I- I 347, Japan;

${ }^{8}$ Department of Respiratory Medicine, lizuka Hospital, 3-83, Yoshio, lizuka, Fukuoka 820-8505, Japan; ${ }^{9}$ Department of Medicine, Koseiren Takaoka Hospital, 5- I , Eiraku, Takaoka, Toyama 933-8555, Japan; ${ }^{10}$ Division of Respiratory Medicine, Kobe City General Hospital, 4-6, Minatojima-nakamachi, Chuo-ku, Kobe, Hyogo 650-0046, Japan; ' 'Department of Integrated Oncology, Institute of Biomedical Research and Innovation, 2-2, Minatojimaminamimachi, Chuo-ku, Kobe, Hyogo 650-0047, Japan; ${ }^{12}$ Department of Respiratory Medicine, Gifu Municipal Hospital, 7-I, Kashima, Gifu 500-8323, Japan; ${ }^{13}$ Division of Medical Oncology and Respiratory Medicine, Faculty of Medicine, Tottori University, 36-I, Nishi-machi, Yonago, Tottori 683-8504, Japan; ${ }^{4}$ Laboratory of Pathology, Toyama University Hospital, Toyama, 2630, Sugitani, Toyama 930-01 94, Japan; ${ }^{15}$ Department of Medical Oncology, Kinki University School of Medicine, Sakai Hospital, 2-7-I, Harayamadai, Minami-ku, Sakai, Osaka 590-0132, Japan

The purpose of this study was to evaluate the efficacy of gefitinib and the feasibility of screening for epidermal growth factor receptor (EGFR) mutations among select patients with advanced non-small cell lung cancer (NSCLC). Stage IIIB/IV NSCLC, chemotherapynaive patients or patients with recurrences after up to two prior chemotherapy regimens were eligible. Direct sequencing using DNA from tumour specimens was performed by a central laboratory to detect EGFR mutations. Patients harbouring EGFR mutations received gefitinib. The primary study objective was response; the secondary objectives were toxicity, overall survival (OS), progression-free survival (PFS), I-year survival (IY-S) and the disease control rate (DCR). Between March 2005 and January 2006,1 I 8 patients were recruited from 15 institutions and were screened for EGFR mutations, which were detected in 32 patients - 28 of whom were enrolled in the present study. The overall response rate was 75\%, the DCR was $96 \%$ and the median PFS was 11.5 months. The median OS has not yet been reached, and the IY-S was 79\%. Thus, gefitinib chemotherapy in patients with advanced NSCLC harbouring EGFR mutations was highly effective. This trial documents the feasibility of performing a multicentre phase II study using a central typing laboratory, demonstrating the benefit to patients of selecting gefitinib treatment based on their EGFR mutation status. British Journal of Cancer (2008) 98, 907-914. doi: I 0.1038/sj.bjc.6604249 www.bjcancer.com

Published online 19 February 2008

(c) 2008 Cancer Research UK

Keywords: epidermal growth factor receptor (EGFR) mutation; gefitinib; non-small cell lung cancer (NSCLC); multicentre prospective phase II; central laboratory

Gefitinib, a tyrosine kinase inhibitor (TKI), is an orally active small molecule that functions as a selective epidermal growth factor receptor (EGFR) inhibitor (Ranson et al, 2002). Two phase II trials (Fukuoka et al, 2003; Kris et al, 2003) for previously treated non-small cell lung cancer (NSCLC) (IDEAL-1 and -2 , respectively) have documented favourable objective responses in $14-18 \%$ of patients. However, in a phase III

*Correspondence: Dr K Tamura;

E-mail: ketamura@ncc.go.jp

Received 4 October 2007; revised II January 2008; accepted I 5 January 2008; published online 19 February 2008 trial (Thatcher et al, 2005), no survival benefit of gefitinib was observed when compared with best-supportive care (BSC) for previously treated NSCLC. In contrast, we have seen a significant survival benefit of erlotinib compared with BSC as a salvage therapy (BR21); erlotinib is also an EGFR-TKI and its chemical structure, which is based on quinazoline, is quite similar to that of gefitinib (Shepherd et al, 2005). Although we do not know whether differences between gefitinib and erlotinib were responsible for these different outcomes, appropriate patient selection to identify good responders is likely crucial for revealing the clinical benefits of the EGFR-TKI family. 
Patient subset analyses of these randomised phase III trials or retrospective trials (Kaneda et al, 2004; Miller et al, 2004) clearly show the existence of populations that are more likely to respond to gefitinib and erlotinib, including women, patients with adenocarcinoma (especially with bronchial alveolar carcinoma (BAC)), nonsmokers and Asian patients (compared with Caucasians). Somatic mutations in specific regions of exons 18,19 and 21 of the ATP-binding domain of EGFR have recently been shown to have strong associations with sensitivity to gefitinib or erlotinib (Lynch et al, 2004; Paez et al, 2004; Pao et al, 2004). Consistent with these findings, the frequencies of these EGFR mutations were higher in women, patients with adenocarcinoma, nonsmokers and Asians, all of whom are among the more frequent responders, as mentioned above (Shigematsu et al, 2005). There are two characteristic types of EGFR mutations. One is the presence of in-frame deletions, including the amino acids at codons 746-750 in exon 19, and the other is an amino-acid substitution at codon 858 (L858R) in exon 21. Recent analyses (Bell et al, 2005) of phase II and III trials for EGFR-TKI, in which patients were not selected based on their mutation status, have suggested that EGFR mutations are correlated with response to therapy but are not correlated with overall survival (OS). Furthermore, EGFR gene amplification/copy number (Cappuzzo et al, 2005; Hirsch et al, 2005) or overexpression (Hirsch et al, 2003) has been shown to be a more useful prognostic marker of response to gefitinib treatment. Patient selection according to EGFR mutation status may yield a superior survival rate by excluding patients who are unlikely to respond to gefitinib treatment. However, other populations that might obtain a clinical benefit from gefitinib treatment, even in the absence of EGFR mutation, may exist.

Three Japanese groups (Asahina et al, 2006; Inoue et al, 2006; Yoshida et al, 2007) have reported prospective phase II studies of gefitinib for advanced-stage NSCLC that were designed to consider the EGFR mutation status of the patients. All of these studies have reported a high response rate and extended progression-free survival (PFS) period, compared with historical controls. However, all of these studies had a relatively short observation period, making the data preliminary. Moreover, the original sample size was calculated after patient selection, and a critical consideration of the suitability of the assay used to detect the mutations (which was performed using small paraffin-embedded specimens obtained from bronchoscopic biopsies), and the estimated EGFR-positive rate were lacking. Additionally, all the trials were conducted at single institutions located in one small area of Japan. Thus, the published data may not be representative of the situation found in general clinical practice throughout Japan and therefore may not directly translate to the general feasibility of gefitinib treatment in Japan.

In view of this situation, we performed a multicentre prospective phase II trial of gefitinib for advanced NSCLC harbouring EGFR mutations. We prospectively registered patients from 15 different institutes in Japan at the beginning of EGFR mutation screening using a central database. Whether or not tissue was available from a bronchoscopic biopsy or surgery was not an inclusion criterion. All the clinical samples from the registered patients were delivered to a central laboratory that then determined the EGFR mutation status or the histological BAC features. The analysis of the survival data was based on a minimum observation period of at least 15 months from the time of entry of the last patient.

\section{MATERIALS AND METHODS}

\section{Eligibility criteria}

Eligible patients had histologically confirmed stage III NSCLC for which thoracic irradiation was not indicated or were stage IV. Chemotherapy-naive patients or those who had previously received up to two prior chemotherapy regimens, including those performed in an adjuvant setting, were eligible. Other eligibility criteria included an age $\geqslant 20$ years, measurable disease, the availability of sufficient amounts of tumour specimen for EGFR mutation analysis, an Eastern Cooperative Oncology Group performance status of $0-2$, adequate organ function $\left(\mathrm{WBC} \leqslant 3000 \mu \mathrm{l}^{-1}\right.$, platelets $\geqslant 75000 \mu \mathrm{l}^{-1}$, AST and $\mathrm{ALT} \leqslant 100 \mathrm{IU}^{-1}$, serum creatinine $\leqslant$ twice the upper limit of the reference range; $P_{\mathrm{aO} 2} \geqslant 60 \mathrm{~mm} \mathrm{Hg}$ ). The exclusion criteria included pulmonary fibrosis, the presence of symptomatic brain metastasis, active concomitant malignancy, severe heart disease, active gastrointestinal bleeding and continuous diarrhoea. All the patients signed a written informed consent form. Approval of this study and the gene analyses were obtained from the Institutional Review Board and the Ethics Committee of each hospital.

\section{EGFR gene analysis}

Tumour specimens were obtained using bronchial fiberscope or surgical procedures. The specimens were fixed with formalin and embedded in paraffin. Four slices $(4-5 \mu \mathrm{m})$ from the embedded block were sent to a central laboratory (Mitsubishi Chemical Safety Institute Ltd., Ibaraki, Japan) for genetic analysis. Most of the tumour specimens were available prior to the registration of this study. Genomic DNA was isolated from specimens using QIAamp Micro kits (QIAGEN KK, Tokyo, Japan). The EGFR mutations in exons 18, 19 and 21, as previously reported (Lynch et al, 2004; Paez et al, 2004), were determined using polymerase chain reaction (PCR) amplification and intron-exon boundary primers according to the published method. An EGFR registrant mutation in exon 20, which was reported by Pao et al (2005) was also examined using PCR and the previously reported primers. Polymerase chain reaction was performed using a Gene Amp PCR System 9700 (Applied Biosystems, Foster City, CA, USA), and the PCR products were confirmed using a Bioanalyzer 2100 (Agilent Technologies Inc., Santa Clara, CA, USA), then sequenced directly using the Big Dye Terminator v3.1 Cycle Sequencing Kit (Applied Biosystems) and ABI PRISM 3100 (Applied Biosystems). All sequencing reactions were performed in both forward and reverse directions and were analysed using the Basic Local Alignment Search Tool (BLAST); all the electropherograms were reanalysed by visual inspection to check for mutations. The presence of an EGFR mutation was confirmed using at least three independent PCR.

All sequence data were sent from the central laboratory to Kinki University. A principle investigator then confirmed whether or not the EGFR mutation status was positive, and the results were sent to the West Japan Thoracic Oncology Group (WJTOG) data centre. The data centre then informed each participating centre of the results of the genetic analysis and requested that the eligibility criteria of the patients be rechecked to insure that only EGFRpositive subjects were registered in the trial. Each tumour was categorised according to histology by a pulmonary pathologist (JF). The percentage of area exhibiting a BAC pattern was also examined to determine the WHO pathological category.

\section{Treatment plan}

Gefitinib (250 mg day ${ }^{-1}$ ) was administered once daily. Treatment was continued uninterrupted until disease progression or intolerable toxicity (grade 4 nonhaematological toxicities, any incidents of interstitial pneumonia or a treatment delay of more than 2 weeks because of adverse effects). Gefitinib administration was delayed if the patient's leukocyte and platelet counts were lower than 1500 and $5000 \mu \mathrm{l}^{-1}$, respectively, and was withheld until these counts had recovered. Gefitinib administration was also delayed if grade 3 or greater nonhaematological toxicities without nausea, vomiting or alopecia occurred and was withheld until recovery to grade 2 . 
Routine clinical and laboratory assessments and chest X-ray assessments were performed weekly or biweekly, where possible; CT examinations of the target lesion were performed every month, and magnetic resonance imaging of the whole brain and a bone scan were performed every 3 months. The objective responses of the patients were evaluated every month using the Response Evaluation Criteria in Solid Tumours (RECIST) guidelines (Therasse et al, 2000). Tumour response was centrally evaluated by independent reviewers at an extramural conference and was performed for the intent-to-treat population. All adverse effects that occurred during gefitinib treatment were reported, and the severity of the effects was graded according to the National Cancer Institute Common Terminology Criteria for Adverse Events, version 3.0.

\section{Statistical analyses}

The primary end point of this study was the response rate. A onestage design using the binominal probability was used to determine the sample size. Assuming that a response rate of $50 \%$ would indicate potential usefulness, whereas a rate of $25 \%$ would be the lower limit of interest, and with $\alpha=0.10$ (two side) and $\beta=0.20$, the estimated accrual number was 23 patients. Estimating that the EGFR-positive rate would be about $20 \%$, the screening number required to accrue 23 EGFR-positive patients was 115 . After assuming an inevaluability rate of $<10 \%$, the final required screening number was 125 .

The secondary end points of this study were toxicity, OS, PFS, 1-year survival (1Y-S) and the disease control rate (DCR). Survival analyses were conducted on the intent-to-treat population using follow-up data available as of 30 April 2007. The survival curves were estimated using Kaplan-Meier plots.

\section{RESULTS}

\section{Patient characteristics}

Between March 2005 and January 2006, 118 patients were prospectively screened from 15 institutions; 117 of them underwent EGFR mutation analysis (tumour tissue was not available for one patient). The median time required for the EGFR mutation analysis was 12 days (range: 7-28 days). Among the 117 patients, EGFR mutations were detected in 32 patients $(27 \%), 14$ of whom had a deletion in or near E746-A750 (including one del E746-T751 ins A, two del L747-T751 and one del L747-T753 ins S) in exon 19. A further 17 had L858R, and one had a L861Q point mutation in exon 21 (Table 1).

Tissue samples from 17 patients (53\%) were obtained by transbronchial biopsy. The EGFR detection rates for the surgical specimens and the bronchoscopic biopsy specimens were similar (30 vs 25\%). The EGFR mutations were significantly more frequent in women $(P \leqslant 0.02)$, in patients with adenocarcinoma $(P=0.001)$ and in people who had never smoked $(P<0.001)$ (Table 2$)$. Finally, 28 patients (14 with deletions in exons 19 and 14 with point mutations in exon 21) were actually registered and received treatment with gefitinib, whereas four patients were dropped from the study as they became ineligible because of tumour progression during the time required for the mutation analysis.

Patient characteristics are listed in Table 3. In the initial screening, there were 56 female patients (48\%), 97 patients $(83 \%)$ with adenocarcinoma and $53(45 \%)$ who had never smoked. The frequency of these characteristics was higher among the patients with EGFR mutations who were actually registered; namely, 18 patients (64\%) were women, 27 (96\%) had adenocarcinoma and 19 (68\%) had never smoked. The median age of the 28 actually registered patients was 68 years; 24 patients $(86 \%)$ had a good performance status $(0-1), 22(79 \%)$ had stage IV diseases and 17
Table I Type of EGFR mutations $(n=32)$

\begin{tabular}{lcr}
\hline Characteristics & No. of patients & $\%$ \\
\hline Exon I8 & 0 & 0 \\
Exon 19 & 14 & 44 \\
del E746-A750 & 10 & 32 \\
del E746-T75I ins A & $\mid$ & 3 \\
del L747-T75 I & 2 & 6 \\
del L747-T753 ins S & 1 & 3 \\
& & 56 \\
Exon 2I & 18 & 53 \\
L858R & 17 & 3 \\
L86 IQ & 1 & \\
\hline
\end{tabular}

EGFR $=$ epidermal growth factor receptor

Table 2 Relationship between patient characteristics and EGFR mutation status

\begin{tabular}{|c|c|c|c|c|c|}
\hline \multirow[b]{2}{*}{ Characteristics } & \multicolumn{2}{|c|}{$\begin{array}{l}\text { EGFR mutation } \\
\text { positive }(n=32)\end{array}$} & \multicolumn{2}{|c|}{$\begin{array}{c}\text { EGFR mutation } \\
\text { negative }(n=85)\end{array}$} & \multirow[b]{2}{*}{$P$} \\
\hline & No. of Patients & $\%$ & No. of Patients & $\%$ & \\
\hline \multicolumn{6}{|l|}{ Sex } \\
\hline Male & II & 34 & 50 & 59 & \\
\hline Female & 21 & 66 & 35 & 41 & $<0.02$ \\
\hline \multicolumn{6}{|l|}{ Histology } \\
\hline Adenocarcinoma & 31 & 97 & 66 & 78 & \\
\hline Nonadenocarcinoma & I & 3 & 19 & 22 & $=0.00 \mathrm{I}$ \\
\hline \multicolumn{6}{|l|}{ Smoking status } \\
\hline Never & 21 & 66 & 31 & 36 & \\
\hline Current/former & 11 & 34 & 54 & 64 & $<0.001$ \\
\hline
\end{tabular}

EGFR = epidermal growth factor receptor.

(61\%) were chemotherapy naive. Thoracic irradiation was contraindicated in one patient with stage IIIA disease because of the large irradiation field that would have been required. All five patients with stage IIIB diseases had malignant effusions. Four patients had received adjuvant therapies; five had received platinum doublets or a combination of gemcitabine and vinorelbine as their first-line therapy. Two patients had received two regimens of platinum doublets followed by docetaxel or pemetrexed. One patient had received local radiation for pain control.

\section{Response and survival}

The objective tumour responses are listed in Table 4 . The overall response rate and DCR were 75\% (95\% CI: 57.6-91.0\%) and 96\% (95\% CI: $87.0-96.4 \%)$, respectively. Five out of ten male patients (50\%), six out of nine smokers $(67 \%)$ and five out of eight male smokers with adenocarcinoma (63\%) achieved a PR. One female nonsmoker with squamous cell carcinoma also achieved a PR. Among the registered patients with EGFR mutations, the response rate was no different between current/former smokers and those who had never smoked (67 vs 79\%) or between chemotherapynaive and postchemotherapy patients (77 vs 73\%). Female and patients with a mutational deletion in exon 19 tended to have a higher response rate than male $(89 v s 50 \%)$ and patients with a missense mutation in exon 21 (86 vs 64\%), respectively.

The median follow-up time was 18.6 months (range: 13.8-23.4 months). The median PFS time was 11.5 months (95\% CI: 7.3 months to -) (Figure 1A). The median OS has not yet been reached, and the $1 \mathrm{Y}-\mathrm{S}$ was $79 \%$ (95\% CI: 63.4-93.8\%) (Figure 1B). 
Table 3 Patient characteristics of all registered patients $(n=28)$

\begin{tabular}{|c|c|}
\hline Characteristics & No. of patients (\%) \\
\hline \multicolumn{2}{|l|}{ Age } \\
\hline Median & 68 \\
\hline Range & $49-89$ \\
\hline \multicolumn{2}{|l|}{ Performance status } \\
\hline 0 & II (39) \\
\hline I & $13(47)$ \\
\hline 2 & $4(14)$ \\
\hline \multicolumn{2}{|l|}{ Sex } \\
\hline Male & $10(36)$ \\
\hline Female & $18(64)$ \\
\hline \multicolumn{2}{|l|}{ Histology } \\
\hline Adenocarcinoma & $27(96)$ \\
\hline Squamous cell carcinoma & I (4) \\
\hline Large cell carcinoma & $0(0)$ \\
\hline Adenosquamous carcinoma & $0(0)$ \\
\hline Other & $0(0)$ \\
\hline \multicolumn{2}{|l|}{ Smoking status } \\
\hline Never & $19(68)$ \\
\hline Current/former & $9(32)$ \\
\hline \multicolumn{2}{|l|}{ Stage } \\
\hline$\| A^{a}$ & I (3) \\
\hline$\||| B$ & $5(18)$ \\
\hline IV & $22(79)$ \\
\hline \multicolumn{2}{|l|}{ Prior cancer therapy } \\
\hline \multicolumn{2}{|l|}{ Chemotherapy } \\
\hline No & $17(61)$ \\
\hline One regimen (adjuvant) & $4(14)$ \\
\hline One regimen (not adjuvant) & $5(18)$ \\
\hline Two regimens & $2(7)$ \\
\hline Recurrence after surgery & II (39) \\
\hline Radiation & I (4) \\
\hline
\end{tabular}

a Unresectable, no indication for thoracic radiation because of a large radiation field.

Table 4 Response rate $(n=28)$

\begin{tabular}{lccc}
\hline Response & No. of patients & Response rate (\%) & $\mathbf{9 5 \%} \mathbf{~ C l}$ \\
\hline Complete response & 1 & 3.6 & \\
Partial response & 20 & 71.4 & \\
Stable disease & 6 & 21.4 & \\
Progressive disease & 0 & 0.0 & \\
Not evaluable & 1 & 3.6 & $57.6-91.0$ \\
Overall response & 21 & 75.0 & $87.0-96.4$ \\
Disease control rate & 27 & 96.4 & \\
\hline Cl=confidence interval. & ${ }^{a}$ One patient was not evaluable because of a poor \\
evaluation of efficacy. & & &
\end{tabular}

\section{Safety and toxicity}

Toxicity was evaluated in all eligible patients (Table 5). The most frequent adverse events were rash, dry skin, diarrhoea, stomatitis and elevated AST/ALT levels. Two patients experienced grade 3 rash and one patient experienced grade 3 keratitis; however, these patients all achieved a PR, and the adverse effects subsided after pausing gefitinib treatment for around 2 weeks. Four patients experienced grade 3 hepatotoxicity; three of these patients had to discontinue treatment for this reason.

One patient developed interstitial lung disease (ILD) (Ando et al, 2006). Ground-glass opacity was detected in the right upper lobe 19 days after the start of gefitinib administration, resulting in the cessation of treatment. However, the lesion enlarged into bilateral lung fields on day 25, and steroid therapy was initiated. Nonetheless, the patient died of respiratory failure on day 48 . Two patients also experienced grade 1 ILD. They recovered without steroid administration.

\section{Subsequent treatment after disease progression}

Of the 14 patients who become refractory to gefitinib and exhibited disease progression, 10 received chemotherapy as their first treatment regimen after gefitinib (Table 6); 5 patients received platinum doublets and 1 patient received vinorelbine as a secondline treatment; and 3 received docetaxel and 1 received platinum doublet as a third-line treatment. In all, 4 out of the 10 patients $(40 \%)$ had a PR. Of the nine patients who become refractory to the first treatment regimen after gefitinib, six received chemotherapy as their second regimen after gefitinib, including one who received gemcitabine, one who received docetaxel, and one who was retreated with gefitinib as a third-line therapy; two other patients received docetaxel and one was re-treated with gefitinib as a fourth-line therapy. Two of the six patients (33\%) had a PR. The two patients who received gefitinib re-treatment both had SD.

\section{BAC features, EGFR amplification and T790M mutation in exon 20}

A total of 110 tissue samples were available for pathological review, of which 90 were from adenocarcinoma; 33 of these specimens (37\%) revealed proportional BAC components in the specimen. Among them, 15 were considered extensive and the remaining 18 were found to have minor BAC components. The 39 surgical specimens included 36 from adenocarcinomas. The EGFR mutations were detected in 12 out of the 36 adenocarcinoma specimens. None of the samples with a BAC component, micropapillary pattern or mucin production was associated with an EGFR mutation (Table 7).

Data on EGFR gene copy numbers were available in only 12 samples. We used the criteria for defining a high EGFR gene copy number (gene amplification or high polysomy, as determined using FISH) that were described in a previous report (Cappuzzo et al, 2005). A total of 7 out of the 12 samples had a high gene copy number (FISH positive), and 6 (3 with EGFR mutations) out of the 7 samples had proportional BAC components. In all, 5 out of the 12 samples were FISH negative, only 1 (with no EGFR mutation) of which had a BAC component. Two patients that were FISH negative, BAC negative and EGFR mutation positive had SD when treated with gefitinib.

Another EGFR mutation, T790M in exon 20, has been reported to be associated with resistance to gefitinib (Kobayashi et al, 2005; Pao et al, 2005). We checked for this mutation in six patients who did not respond to gefitinib; however, the mutation could not be identified in any of the patients.

\section{DISCUSSION}

We performed a multicentre phase II study examining the use of gefitinib for advanced NSCLC in patients with EGFR mutations, prospectively recruiting patients at the time of genetic screening and avoiding a selection bias. All patients were registered in a central database. All tissues were delivered from the local participants to the central facility, where they were reviewed by a pathology specialist and the EGFR mutation status was evaluated. The median time for the EGFR mutation detection analysis was 12 days, which is probably an acceptable time lag before the start of treatment for advanced NSCLC. However, a shorter period would clearly be desirable for routine clinical practice. Indeed, 4 out of the 32 EGFR-positive patients were dropped from the study because of disease progression before their actual registration 

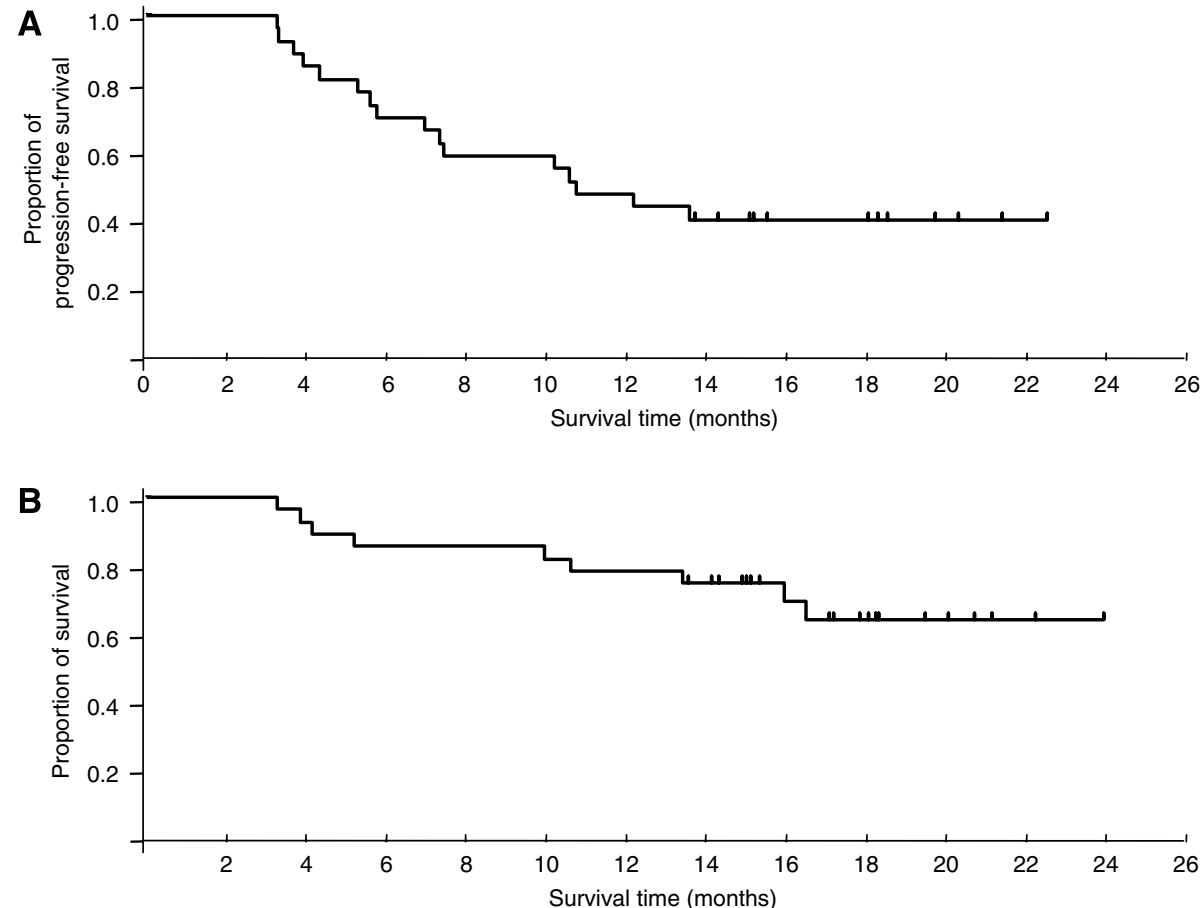

Figure I (A) Progression-free survival (PFS) and (B) overall survival (OS) of all eligible patients $(n=28)$. The median PFS was II.5 months. The median OS has not yet been reached. The I-year survival rate was $79 \%$.

Table 5 Common adverse events $(n=28)$

\begin{tabular}{|c|c|c|c|c|}
\hline \multirow[b]{2}{*}{ Adverse events } & \multicolumn{4}{|c|}{ No. of patients (\%) } \\
\hline & Grade I & Grade 2 & Grade 3 & Grade 4 \\
\hline \multicolumn{5}{|l|}{ Haematologic } \\
\hline Anaemia & $12(43)$ & $3(11)$ & $0(0)$ & $0(0)$ \\
\hline Leucopaenia & $4(14)$ & I (4) & $2(7)$ & $0(0)$ \\
\hline Neutropaenia & $4(14)$ & I (4) & I (4) & $0(0)$ \\
\hline Thrombocytopaenia & $3(11)$ & $0(0)$ & $0(0)$ & $0(0)$ \\
\hline \multicolumn{5}{|l|}{ Nonhaematologic } \\
\hline Rash & $10(36)$ & II (39) & $2(7)$ & $0(0)$ \\
\hline Dry skin & $9(32)$ & $10(36)$ & $0(0)$ & $0(0)$ \\
\hline Nail changes & $5(18)$ & $2(7)$ & $0(0)$ & $0(0)$ \\
\hline Keratitis & $0(0)$ & $0(0)$ & I (4) & $0(0)$ \\
\hline Fever & $0(0)$ & I (4) & $0(0)$ & $0(0)$ \\
\hline Fatigue & $3(10)$ & $3(10)$ & $3(10)$ & $0(0)$ \\
\hline Diarrhoea & $7(25)$ & I (4) & $0(0)$ & $0(0)$ \\
\hline Constipation & I (4) & $0(0)$ & $0(0)$ & $0(0)$ \\
\hline Stomatitis & $8(29)$ & I (4) & $0(0)$ & $0(0)$ \\
\hline Gastritis & I (4) & $0(0)$ & $0(0)$ & $0(0)$ \\
\hline Anorexia & $2(7)$ & I (4) & $0(0)$ & $0(0)$ \\
\hline Nausea & $3(1 \mid)$ & I (4) & $0(0)$ & $0(0)$ \\
\hline Vomiting & $2(7)$ & $2(7)$ & I (4) & $0(0)$ \\
\hline Dyspnoea & $2(7)$ & $0(0)$ & I (4) & $0(0)$ \\
\hline ILD & $2(7)$ & $0(0)$ & $0(0)$ & I (4) \\
\hline Vertigo & I (4) & I (4) & $0(0)$ & $0(0)$ \\
\hline Dysgeusia & $0(1)$ & I (4) & $0(0)$ & $0(0)$ \\
\hline Elevated AST/ALT & $10(36)$ & $2(7)$ & $4(14)$ & $(4)^{a}$ \\
\hline Elevated creatinine & $2(7)$ & I (4) & $2(7)$ & $0(0)$ \\
\hline
\end{tabular}

$\mathrm{ALT}=$ alanine transaminase; $\mathrm{AST}=$ aspartate transaminase; $\| \mathrm{LD}=$ interstitial lung disease. ${ }^{a}$ Same patient.

could occur. Yatabe et al (2006) has developed a rapid assay to detect EGFR mutations, and we have decided to use this assay in a phase III trial. The EGFR mutation rates in transbronchial biopsy samples were found to be the same as those in surgical specimens, suggesting that this assay can also accommodate stage IV NSCLC. We detected the two characteristic types of EGFR mutations (in exons 19 and 21 ) in 44 and $56 \%$ of the patients, respectively (Table 1); these percentages are identical to those in previous reports from Japan (Shigematsu et al, 2005; Asahina et al, 2006; Inoue et al, 2006; Yatabe et al, 2006; Yoshida et al, 2007). In summary, we confirmed the feasibility of using the EGFR detection assay in daily practice.

The overall response rate was $75 \%$, which was comparable to those of other phase II studies of gefitinib in patients with EGFR mutations (Asahina et al, 2006; Inoue et al, 2006), despite our study permitting the entry of patients who had previously received up to two chemotherapy regimens. The DCR of $96 \%$ was relatively high, and the median PFS of 11.5 months and 1 Y $-S$ of $79 \%$ were also very promising. In a Korean study, Lee et al (2006) also reported a very promising response rate $(56 \%)$ and $1 Y-S(76 \%)$ for gefitinib in a prospective study of selected NSCLC patients with adenocarcinoma and never/light smokers, defined as having smoked no more than 100 cigarettes during one's lifetime. In the screening process for the present study, EGFR mutations were significantly more frequent in women, patients with adenocarcinoma and those who had never smoked. However, among the patients who were selected according to their EGFR mutation status, no differences in response were observed between never smokers and current/former smokers or between chemotherapynaive and postchemotherapy patients. In a retrospective study, Han et al (2006) directly compared clinical predictors (smoking history, gender and histology) and the EGFR mutation status for their ability to predict response and survival. They showed that female never smokers with adenocarcinoma (three clinical predictors) had a $33 \%$ response rate, whereas patients with a positive EGFR mutation status had a $62 \%$ response rate. Furthermore, in a multivariate analysis, only a positive EGFR mutation status was associated with an improved OS, suggesting that the EGFR mutation status should be analysed whenever possible to optimise response predictions based on clinical 
Table 6 Subsequent treatments after failure to respond to gefitinib $(n=28)$

\begin{tabular}{|c|c|c|c|c|c|}
\hline Gefitinib treatment & No. of Patients & $\begin{array}{l}\text { Ist regimen } \\
\text { after gefitinib }\end{array}$ & No. of patients & $\begin{array}{l}\text { 2nd regimen } \\
\text { after gefitinib }\end{array}$ & No. of patients \\
\hline Ist line & 17 & Plt doublet & 5 & $\begin{array}{l}\text { Gem or Doce } \\
\text { Gefitinib }^{a}\end{array}$ & $\begin{array}{l}2 \\
1\end{array}$ \\
\hline \multirow[t]{2}{*}{ 2nd line ${ }^{b}$} & 4 & Doce & 2 & Doce & । \\
\hline & & Plt doublet & I & Doce & I \\
\hline 2nd line & 5 & Doce & 1 & $G_{\text {Gitinib }}{ }^{a}$ & I \\
\hline Response & & & $4 / 10$ & & $2 / 6$ \\
\hline
\end{tabular}

Doce $=$ docetaxel; $G$ em $=$ gemcitabine; Plt = platinum; VNR = vinorelbine. ${ }^{a}$ Both patients had an SD response after gefitinib re-treatment. ${ }^{b}$ First regimen as systemic chemotherapy after adjuvant treatment.

Table 7 Bronchial alveolar carcinoma (BAC) features and EGFR mutation status

\begin{tabular}{lccc}
\hline & \multicolumn{2}{c}{ EGFR mutation } & \\
\cline { 2 - 3 } & $\boldsymbol{+}$ & - & P-value \\
\hline Surgically resected adenocarcinoma case & 12 & 24 & \\
BAC component & & & \\
Yes & 8 & 17 & 1.0 \\
No & 4 & 7 & \\
Micropapillary pattern & & & \\
Yes & 4 & 12 & 0.48 \\
No & 8 & 12 & \\
Mucin production & & & \\
Yes & & & \\
No & 1 & 5 & 1.0 \\
\hline
\end{tabular}

$E G F R=$ epidermal growth factor receptor.

background factors. In the present study, EGFR mutations were detected in 16 out of $40(40 \%)$ female never smokers with adenocarcinoma who underwent the screening process, and 14 out of these 16 patients $(88 \%)$ achieved a response after undergoing gefitinib therapy. We could not compare the predictive powers of clinical predictors and the EGFR mutation status with regard to the clinical benefits of gefitinib in this study. Thus, the need for EGFR mutation testing among clinically favourable patients remains uncertain. Decisions regarding the first-line therapy of choice for patients with EGFR mutations or a clinically favourable profile (nonsmoker with adenocarcinoma) must also await the results of an ongoing randomised phase III study in an Asian population (IPASS: Iressa Pan-Asian Study) comparing platinum doublets with gefitinib.

In contrast, $50 \%$ of the men, $67 \%$ of the smokers and $63 \%$ of the men who were smokers achieved a PR in this study. Furthermore one female nonsmoker with squamous cell carcinoma also responded to gefitinib. The histological type of this tumour was reassigned by a pulmonary pathologist, and the tumour was finally confirmed to be a squamous cell carcinoma. Squamous cell carcinoma harbouring an EGFR mutation is rarely seen but has been previously reported (Asahina et al, 2006). In a Japanese phase II trial of gefitinib for unselected chemotherapy-naive patients (Niho et al, 2006), the response rates among smokers, men, and patients with nonadenocarcinoma were 19,13 and $10 \%$, respectively. Thus, NSCLC patients who are either smokers, men or have a nonadenocarcinoma histology are unlikely to receive gefitinib treatment as a first-line treatment instead of standard chemotherapies (platinum doublets), which yield a response rate of about $30 \%$ (Schiller et al, 2002). Therefore, EGFR mutation screening may have a higher impact on the selection of responders to gefitinib treatment among these kinds of Asian patient subset (for example, smokers with adenocarcinoma, and nonsmoking men or women with nonadenocarcinoma).

The benefit of chemotherapy in general among patients with EGFR mutations, compared with EGFR mutation-negative patients, remains uncertain. Previous studies (Bell et al, 2005) have suggested that patients with EGFR mutations tend to be more sensitive to chemotherapy than those with wild-type EGFR. In the present study, 40 and $33 \%$ of the patients responded to first- and second-line chemotherapy regimens after gefitinib, respectively. These relatively high response rates for refractory NSCLC suggest that patients with an EGFR mutation-positive status are generally sensitive to chemotherapy. Large-scale multivariate analyses, using pooled data from prospective phase II or III trials in which the EGFR mutation status was clearly confirmed, are needed to clarify this point.

The toxicities observed in the present study were mostly tolerable. Most of the common adverse events, like rash, diarrhoea or hepatotoxicity, were mild and subsided after gefitinib administration was paused for a short period. One male smoker with adenocarcinoma died of ILD. Thus, even among patients who are selected based on their EGFR mutation status, men or smokers may still be at risk for developing ILD; therefore, biomarkers to predict ILD are needed.

Patients with exon 19 mutations tended to have a higher response rate than those with a missense mutation in exon 21 , consistent with the findings of previous reports (Jackman et al, 2006; Riely et al, 2006). The Spanish Lung Cancer Group also reported on a prospective phase II study of erlotinib in advanced NSCLC patients with EGFR mutations (Paz-Ares et al, 2006). The overall response rate was $82 \%$. They also showed a difference in response rates between patients with mutations in exons 19 and 21 (95 and 67\%, respectively). Exon $11 \mathrm{c}$-kit mutations are more closely correlated with a good prognosis in patients with gastrointestinal stromal tumour, who may benefit from lower doses of imatinib, whereas patients with exon 9 mutations may require higher doses (DebiecRychter et al, 2006). In the case of EGFR, functional differences between mutation types may also exist.

We found no discernible associations between the EGFR mutation frequency and the presence of a BAC component. Several reports, including that of Hirsch et al (2005) suggest that a higher EGFR copy number is correlated with BAC histological features. We also found an association between a high EGFR copy number and the presence of a BAC component, even though the number of specimens examined was relatively small. In a study on erlotinib, the presence of a BAC component was clearly associated with EGFR amplification. As the EGFR mutation rate is lower in western populations than in Asian populations, the EGFR gene copy number might be a more useful biomarker in western populations, especially with regard to the use of erlotinib. 
In conclusion, gefitinib treatment for patients with advanced NSCLC harbouring an EGFR mutation demonstrated a promising activity in patients with a good performance status. Patient screening according to EGFR mutation status may be a useful tool in daily practice and will likely have a great impact on the selection of patients who are likely to benefit from gefitinib treatment.

\section{REFERENCES}

Asahina H, Yamazaki K, Kinoshita I, Sukoh N, Harada M, Yokouchi H, Ishida T, Ogura S, Kojima T, Okamoto Y, Fujita Y, Dosaka-Akita H, Isobe $\mathrm{H}$, Nishimura M, on behalf of the Hokkaido Lung Cancer Clinical Study Group (2006) A phase II trial of gefitinib as first-line therapy for advanced non-small cell lung cancer with epidermal growth factor receptor mutations. Br J Cancer 95: 998-1004

Ando M, Okamoto I, Yamamoto N, Takeda K, Tamura K, Seto T, Ariyoshi Y, Fukuoka M (2006) Predictive factors for interstitial lung disease, antitumor response and survival in non-small-cell lung cancer patients treated with gefitinib. J Clin Oncol 24: 2549-2556

Bell DW, Lynch TJ, Haserlat SM, Harris PL, Okimoto RA, Brannigan BW, Sgroi DC, Muir B, Riemenschneider MJ, Iacona RB, Krebs AD, Johnson DH, Giaccone G, Herbst RS, Manegold C, Fukuoka M, Kris MG, Baselga J, Ochs JS, Haber DA (2005) Epidermal growth factor receptor mutations and gene amplification in non-small-cell lung cancer: molecular analysis of the IDEAL/INTACT gefitinib trials. J Clin Oncol 23: 8081-8092

Cappuzzo F, Hirsch FR, Rossi E, Bartolini S, Ceresoli GL, Bemis L, Haney J, Witta S, Danenberg K, Domenichini I, Ludovini V, Magrini E, Gregorc V, Doglioni C, Sidoni A, Tonato M, Franklin WA, Crino L, Bunn Jr PA, Varella-Garcia M (2005) Epidermal growth factor receptor gene and protein and gefitinib sensitivity in non-small-cell lung cancer. $J$ Natl Cancer Inst 97: 643-655

Debiec-Rychter M, Sciot R, Le Cesne A, Schlemmer M, Hohenberger P, van Oosterom AT, Blay JY, Leyvraz S, Stul M, Casali PG, Zalcberg J, Verweij J, Van Glabbeke M, Hagemeijer A, Judson I, EORTC Soft Tissue and Bone Sarcoma Group, The Italian Sarcoma Group, Australasian GastroIntestinal Trial Group (2006) KIT mutations and dose selection for imatinib in patients with advanced gastrointestinal stromal tumours. Eur J Cancer 42: $1093-1103$

Fukuoka M, Yano S, Giaccone G, Tamura T, Nakagawa K, Douillard JY, Nishiwaki Y, Vansteenkiste J, Kudoh S, Rischin D, Eek R, Horai T, Noda K, Takata I, Smit E, Averbuch S, Macleod A, Feyereislova A, Dong RP, Baselga J (2003) Multi-institutional randomized phase II trial of gefitinib for previously treated patients with advanced non-small-cell lung cancer. J Clin Oncol 21: 2237-2246

Han SW, Kim TY, Lee KH, Hwang PG, Jeon YK, Oh DY, Lee SH, Kim DW, Im SA, Chung DH, Heo DS, Bang YJ (2006) Clinical predictors versus epidermal growth factor receptor mutation in gefitinib-treated nonsmall-cell lung cancer patients. Lung Cancer 54: 201-207

Hirsch FR, Varella-Garcia M, Bunn Jr PA, Di Maria MV, Veve R, Bremmes RM, Barón AE, Zeng C, Franklin WA (2003) Epidermal growth factor receptor in non-small-cell lung carcinomas: correlation between gene copy number and protein expression and impact on prognosis. J Clin Oncol 21: $3798-3807$

Hirsch FR, Varella-Garcia M, McCoy J, West H, Xavier AC, Gumerlock P, Bunn Jr PA, Franklin WA, Crowley J, Gandara DR, Southwest Oncology Group (2005) Increased epidermal growth factor receptor gene copy number detected by fluorescence in situ hybridization associates with increased sensitivity to gefitinib in patients with bronchioloalveolar carcinoma subtypes: a Southwest Oncology Group Study. J Clin Oncol 23: $6838-6845$

Inoue A, Suzuki T, Fukuhara T, Maemondo M, Kimura Y, Morikawa N, Watanabe H, Saijo Y, Nukiwa T (2006) Prospective phase II study of gefitinib for chemotherapy-naïve patients with advanced non-small cell lung cancer with epidermal growth factor receptor gene mutations. J Clin Oncol 24: 3340 - 3346

Jackman DM, Yeap BY, Sequist LV, Lindeman N, Holmes AJ, Joshi VA, Bell DW, Huberman MS, Halmos B, Rabin MS, Haber DA, Lynch TJ, Meyerson M, Johnson BE, Jänne PA (2006) Exon 19 deletion mutation of epidermal growth factor receptor are associated with prolonged survival in non-small cell lung cancer patients treated with gefitinib or erlotinib. Clin Cancer Res 12: 3908-3914

\section{ACKNOWLEDGEMENTS}

We thank Masaru Sekijima, PhD (Director, Research Division for Advanced Technology, Kashima Laboratory, Mitsubishi Chemical Institute Ltd) for technical support with the EGFR mutation analyses, and Yuki Inoue, Erina Hatashita and Yuki Yamada for data management.

Kris MG, Natale RB, Herbst RS, Lynch Jr TJ, Prager D, Belani CP, Schiller JH, Kelly K, Spiridonidis H, Sandler A, Albain KS, Cella D, Wolf MK, Averbuch SD, Ochs JJ, Kay AC (2003) Efficacy of gefitinib, an inhibitor of the epidermal growth factor receptor tyrosine kinase, in symptomatic patients with non-small-cell lung cancer. JAMA 290: 2149-2158

Kaneda H, Tamura K, Kurata T, Uejima H, Nakagawa K, Fukuoka M (2004) Retrospective analysis of the predictive factors associated with response and survival benefit of gefitinib in patients with advanced non-small cell lung cancer. Lung Cancer 46: 247 -254

Kobayashi S, Boggon TJ, Dayaram T, Jänne PA, Kocher O, Meyerson M, Johnson BE, Eck MJ, Tenen DG, Halmos B (2005) EGFR mutation and resistance of non-small-cell lung cancer to gefitinib. $N$ Engl J Med 352: $786-792$

Lee DH, Han JY, Yu SY, Kim HY, Nam BH, Hong EK, Kim HT, Lee JS (2006) The role of gefitinib treatment for Korean never-smokers with advanced or metastatic adenocarcinoma of lung: a prospective study. J Thorac Oncol 1: $965-971$

Lynch TJ, Bell DW, Sordella R, Gurubhagavatula S, Okimoto RA, Brannigan BW, Harris PL, Haserlat SM, Supko JG, Haluska FG, Louis DN, Christiani DC, Settleman J, Haber DA (2004) Activating mutations in the epidermal growth factor receptor underlying responsiveness of non-small-cell lung cancer to gefitinib. $N$ Engl J Med 350: 2129-2139

Miller VA, Kris MG, Shah N, Patel J, Azzoli C, Gomez J, Krug LM, Pao W, Rizzo B, Tyson L, Venkatraman E, Ben-Porat L, Memoli N, Zakowski M, Rusch V, Heelan RT (2004) Bronchioloalveolar pathologic subtype smoking history predicts sensitivity to gefitinib in advanced non-smallcell lung cancer. J Clin Oncol 22: 1103-1109

Niho S, Kubota K, Goto K, Yoh K, Ohmatsu H, Kakinuma R, Saijo N, Nishiwaki Y (2006) First-line single agent treatment with gefitinib in patients with advanced non-small-cell lung cancer: a phase II study. J Clin Oncol 24: 64-69

Paez JG, Janne PA, Lee JC, Tracy S, Greulich H, Gabriel S, Herman P, Kaye FJ, Lindeman N, Boggon TJ, Naoki K, Sasaki H, Fujii Y, Eck MJ, Sellers WR, Johnson BE, Meyerson M (2004) EGFR mutation in lung cancer: correlation with clinical response to gefitinib therapy. Science 304: $1497-1500$

Paz-Ares L, Sanchez JM, Garcia-Velasco A, Masuti B, Majem M, LopezVivanco G, Provencio M, Montes A, Amador M, Rosell R (2006) A prospective phase II trial if erlotinib in advanced non-small cell lung cancer (NSCLC) patients with mutations in the tyrosine kinase (TK) domain of the epidermal growth factor receptor (EGFR). Proc Am Soc Clin Onc 24(Suppl): abstract 7020

Pao W, Miller VA, Zakowski MF, Doherty J, Politi KA, Sarkaria I, Singh B, Varmus H (2004) EGF receptor gene mutations are common in lung cancers from 'never smokers' and are associated with sensitivity of tumors to gefitinib and erlotinib. Proc Natl Acad Sci USA 101: 1330613311

Pao W, Miller VA, Politi KA, Riely GJ, Somwar R, Zakowski MF, Kris MG, Varmus H (2005) Acquired resistance of lung adenocarcinomas to gefitinib or erlotinib is associated with a second mutation in the EGFR kinase domain. PLoS Med 2: 1-11

Ranson M, Hammond LA, Ferry D, Kris M, Tullo A, Murray PI, Miller V, Averbuch S, Ochs J, Morris C, Feyereislova A, Swaisland H, Rowinsky EK (2002) ZD1839, a selective oral epidermal growth factor receptor-tyrosine kinase inhibitor, is well tolerated and active in patients with solid, malignant tumors: results of a phase I trial. J Clin Oncol 20: $2240-2250$

Riely GJ, Pao W, Pham D, Li AR, Rizvi N, Venkatraman ES, Zakowski MF, Kris MG, Ladanyi M, Millar VA (2006) Clinical course of patients with non-small cell lung cancer and epidermal growth factor receptor exon 19 and exon 21 mutations treated with gefitinib or erlotinib. Clin Cancer Res 12: $839-844$ 
Schiller JH, Harrington D, Belani CP, Langer C, Sandler A, Krook J, Zhu J, Jhonson DH, Eastern Cooperative Oncology Group (2002) Comparison of four chemotherapy regimens for advanced non-small cell lung cancer. N Engl J Med 346: $92-98$

Shepherd FA, Rodrigues Pereira J, Ciuleanu T, Tan EH, Hirsh V, Thongprasert S, Compos D, Maoleekoonpiroj S, Smylie M, Martins R, van Kooten M, Dediu M, Findlay B, Tu D, Johnston D, Bezjak A, Clark G, Santabarbara P, Seymour L, National Cancer Institute of Canada Clinical Trials Group (2005) Erlotinib in previously treated non-small cell lung cancer. $N$ Engl J Med 353: $123-132$

Shigematsu H, Lin L, Takahashi T, Nomura M, Suzuki M, Wistuba II, Fong KM, Lee H, Toyooka S, Shimizu N, Fujisawa T, Feng Z, Roth JA, Herz J, Minna JD, Gazdar AF (2005) Clinical and biological features associated with epidermal growth factor receptor gene mutations in lung cancers. J Natl Cancer Inst 97: 339-346

Thatcher N, Chang A, Parikh P, Rodrigues Pereira J, Ciuleanu T, von Pawel J, Thongprasert S, Tan EH, Pemberton K, Archer V,

Carroll K (2005) Gefitinib plus best supportive care in previously treated patients with refractory advanced non-small-cell lung cancer: results from a randomised placebo-controlled, multicentre study (Iressa Survival Evaluation in Lung Cancer). Lancet 366: $1527-1537$

Therasse P, Arbuck SG, Eisenhauer EA, Wanders J, Kaplan RS, Rubinstein L, Verweij J, Van Glabbeke M, van Oosterom AT, Christian MC, Gwyther SG (2000) New guidelines to evaluate the response to treatment in solid tumors. J Natl Cancer Inst 92: 205-216

Yatabe Y, Hida T, Horio Y, Kosaka T, Takahashi T, Mitsudomi T (2006) A rapid, sensitive assay to detect EGFR mutation in small biopsy specimens from lung cancer. J Mol Diagn 8: 335-341

Yoshida K, Yatabe Y, Young Ji P, Shimizu J, Horio Y, Matsuo K, Kosaka T, Mitsudomi T, Hida T (2007) Prospective validation for prediction of gefitinib sensitivity by epidermal growth factor receptor gene mutation in patients with non-small cell lung cancer. $J$ Thoracic Oncol 2: 22-28 